\title{
O ACERVO NIETZSCHE NA BIBLIOTECA HERZOGIN ANNA AMALIA EM WEIMAR
}

\author{
Nietzsche's collections at Herzogin \\ Anna Amalia library in Weimar
}

\section{Erdmann von Wilamowitz-Moellendorff}

Bibliotecário. Responsável pelo Acervo-Nietzsche da Biblioteca Herzogin Anna Amalia em Weimar. Tradução: Antonio Edmilson Paschoal. Revisão: Anna Hartmann Cavalcanti e Jorge Luiz Viesenteiner. Weimar, Alemanha, e-mail: erdmann.wilamowitz@klassik-stiftung.de

\section{Resumo}

A biblioteca de Nietzsche e a biblioteca do antigo Arquivo-Nietzsche de Weimar são hoje parte efetiva do Acervo-Nietzsche da Biblioteca Herzogin Anna Amalia em Weimar de Weimar. Ambas as bibliotecas são aqui apresentadas em um esboço histórico.

Palavras-chave: Biblioteca de Nietzsche; Leituras de Nietzsche; ArquivoNietzsche Weimar; Biblioteca Herzogin Anna Amalia; Acervos-Nietzsche.

\section{Abstract}

Nietzsche's library as well as the library of the former Nietzsche's Collections of Weimar constitute, at present, a permanent part of Nietzsche's Collections at Herzogin Anna Amalia Library, in Weimar. The history of both libraries is here summarily described.

Keywords: Nietzsche's Library; Nietzsche's Readings; Weimar Nietzsche-Archive; Nietzsche's Collections; Herzogin Anna Amalia Library. 
Os livros acompanharam Nietzsche ao longo de toda a sua vida. Ele foi um trabalhador do espírito, que se confrontava de forma intensiva com as ideias de outros pensadores. Esse confronto era, por sua vez, conduzido diretamente para o interior de suas obras, para onde afluíam, igualmente, suas leituras. Pode-se dizer que, até os seus livros tornarem-se "dinamites", Nietzsche leva a cabo um considerável processo de recepção intelectual, e que as suas leituras tomam parte essencialmente desta "química" e, em função disto, também sua biblioteca. Sua biblioteca, que se encontra no foco de pesquisa, como raramente ocorre com outros pensadores, é hoje parte efetiva do AcervoNietzsche da Biblioteca de Weimar. Tal acervo compreende três partes:

1. a biblioteca póstuma de Nietzsche com cerca de 1.400 volumes;

2. a biblioteca do antigo Arquivo-Nietzsche de Weimar com cerca de 6.000 volumes;

3. a coletânea de escritos sobre Nietzsche da Biblioteca de Weimar, reunida de forma ininterrupta desde 1955 e que hoje compreende mais de 6.000 volumes.

O principal ponto da exposição situa-se, naturalmente, na biblioteca de Nietzsche, ela é o domínio mais valioso do Acervo-Nietzsche de Weimar, e se encontra organizada por meio de um catálogo especial e sistemático (fichário), assim como exposta de forma integral no catálogo online ${ }^{1}$ (OPAC) da Biblioteca Herzogin Anna Amalia. Em função da estreita ligação com o tema, o novo catálogo da Biblioteca Nietzsche, que teve início no ano de 2003, também será detalhado na sequência.

\section{A biblioteca de Nietzsche (Números de registro C 1 - C 775)}

Em meio às inúmeras vicissitudes da história alemã do século XX, a biblioteca deixada por Nietzsche, ou o que dela foi conservado, foi transferida para a Biblioteca Herzogin Anna Amalia de Weimar. Ela forma nos AcervosNietzsche de Weimar um domínio substancialmente fechado e organizado com os números de registro $\mathrm{C} 1$ até $\mathrm{C}$ 775. Os exemplares manuscritos da edição de sua própria obra encontram-se dispostos no acervo da biblioteca do antigo

1 Fundação Weimar Clássica: <http://www.klassik-stiftung.de/forschung/onlinedatenbanken.html> ou diretamente em: 〈http://opac.ub.uni-weimar.de/DB=2/> 
Arquivo-Nietzsche. No Arquivo Goethe-Schiller de Weimar encontram-se hoje 133 livros e impressos, que são igualmente um suplemento da biblioteca de Nietzsche, em meio a quase todas as partituras musicais de propriedade de Nietzsche. Ao todo estão conservados ainda hoje em torno de 1.400 volumes da biblioteca de Nietzsche, os quais, depois do colapso de Nietzsche em Turin, nos primeiros dias do mês de janeiro de 1889 , foram recolhidos por sua mãe e por sua irmã a partir de diferentes localidades e reunidos, primeiramente em Naumburg e, desde 1896, no Arquivo-Nietzsche de Weimar.

A biblioteca de Nietzsche não possui o caráter de uma biblioteca erudita e sistematicamente reunida, ao contrário, em seu formato fragmentário, ela oferece testemunho da movimentada vida de seu proprietário. Pelas mais diferentes maneiras, muitos de seus livros deixaram de ser propriedade de Nietzsche ainda no decorrer de sua vida. Isto é perceptível, na medida em que apenas algumas poucas obras de cunho literário permaneceram no seu acervo. Elisabeth Förster-Nietzsche escreve que ele teria dado de presente muitos livros de literatura. Aliás, ele colocou à venda muitos livros no antiquário, em especial depois de ter renunciado às suas atividades docentes na Basileia e nos dez anos em que sobreviveu como filósofo livre e errante. O número relativamente grande de livros que permaneceu da época de juventude e de estudante, bem como dos anos em que foi professor de filologia, se deve ao engajamento de Elisabeth FörsterNietzsche. Desde os tempos de juventude ela já assume a guarda de livros de Nietzsche. No ano de 1881 ela resgatou a biblioteca da Basileia de Nietzsche, ${ }^{2}$ incluindo livros com os vestígios de seu trabalho como filólogo, de uma venda iminente e, em 1886, entregou-os à sua mãe para serem guardados em Naumburg.

Ainda hoje a literatura do período clássico constitui a maior parte dos livros de Nietzsche que foram conservados. Outro grupo relativamente grande é formado pelos livros de filosofia mais recentes. Também outras áreas como religião, educação, ciências naturais, história e geografia, etnologia, direito, estética, história da arte e da cultura assim como literatura e história da literatura estão parcialmente ali representados, contudo, apenas em pequenos grupos.

Existem atualmente apenas poucos testemunhos escritos sobre a forma como os livros foram reunidos. Alguns podem ser retirados de um relatório feito por Elisabeth Förster-Nietzsche na coletânea "Livros e caminhos de livros" do ano de 1900. Outros pormenores são encontrados nas cartas

A este respeito, comparar também: METTE, H. J. Sachlicher Vorbericht. In: Nietzsche: Werke und Briefe. Historisch-Kritische Gesamtausgabe. v. 1: Jugendschriften 1854-1861. München 1933. P. CII-CIII. 
trocadas entre Franz Overbeck e Franziska Nietzsche, a mãe do filósofo. Até hoje muito pouco foi publicado sobre a história da biblioteca de Nietzsche, com exceção do escrito mencionado de Elisabeth Förster-Nietzsche, que também reuniu o primeiro inventário impresso sobre o tema, o catálogo de Max Oehler levado a público em 1942, ${ }^{3}$ além do estudo sobre a história do Arquivo-Nietzsche, de David Marc Hoffmann (1991). ${ }^{4}$ A mais importante entre as publicações recentes sobre o tema é o estudo introdutório "História da Biblioteca de Nietzsche e seus registros" ${ }^{5}$ feito por Paolo D'Iorio para o novo catálogo da Biblioteca de Nietzsche (2003).

$\mathrm{Na}$ época do colapso de Nietzsche os livros e manuscritos estavam espalhados em diferentes localidades. Algumas caixas com livros e manuscritos, especialmente os do tempo de juventude e de estudante, já eram guardados pela mãe em Naumburg, desde 1886. Também Overbeck mantinha consigo alguns livros e manuscritos. Outros livros encontravam-se em Sils-Maria e outros em Turin. Esses livros foram recolhidos por Overbeck e conduzidos para a Basileia, e dali então foram enviados para a mãe de Nietzsche em Naumburg, em 1892. E 1899 Elisabeth Förster-Nietzsche encontrou ainda com a proprietária genovesa de uma pensão onde Nietzsche se hospedava, livros e manuscritos, que em 1883 ele tinha entregado para serem ali guardados. Ela escreve a respeito: "a caixa estava, entretanto, se desfazendo em pedaços. Contudo, a escrupulosa senhora tinha preservado cuidadosamente o conteúdo" (ELIZABETHNIETZSCHE, 1900, p. 446).

Desde 1896 os livros foram guardados em Weimar no "ArquivoNietzsche" fundado por Elisabeth Förster-Nietzsche. Inicialmente foram guardados no primeiro domicílio do Arquivo em Weimar na rua Wörth, atual rua Thomas-Müntzer, número 5, e a partir da metade do ano de 1897 na moradia "Silberblick" (vista prateada), adquirida por Meta Von Salis e colocada à disposição da senhora Förster-Nietzsche. Ali, após a reforma da casa por Henry van de Velde 1902/1903, os livros foram colocados em um novo e grande salão e disponibilizados para os trabalhos de preparação da edição das Obras

Biblioteca de Nietzsche / [organizada e prefaciada por Max Oehler]. Weimar 1942. VIII, 56 p. 4 vol. (Ill.). (Contribuição anual da Sociedade dos Amigos do Arquivo-Nietzsche; 14)

4 HOFFMANN, D. M. Zur Geschichte des Nietzsche-Archivs. Berlin: New York 1991. (Supplementa Nietzscheana; 2).

5 D'IORIO, Paolo: Geschichte der Bibliothek Nietzsches und ihrer Verzeichnisse. - In: Nietzsches persönliche Bibliothek. Berlin, New York: Walter Gruyter, 2003. p. 33-77. 
Completas de Nietzsche $(\mathrm{GA})^{6}$ e, mais tarde, disponibilizados também para a editoração inacabada dos fragmentos, na Edição Histórico-Crítica, publicada pela editora Beck (BAW / BAB). ${ }^{7}$

Desde cedo Elisabeth Förster-Nietzsche reconheceu o significado da Biblioteca de Nietzsche, razão pela qual ela pensava em fazer a sua catalogação. Em janeiro de 1896 ela ofereceu a tarefa de preparar este catálogo ${ }^{8}$ a Rudolf Steiner, que nessa época trabalhava como colaborador na EdiçãoSofia das obras de Goethe no Arquivo Goethe-Schiller em Weimar. No mesmo mês, Steiner se encarregou desta tarefa e produziu o primeiro catálogo por escrito da Bibioteca de Nietzsche. O manuscrito se encontra ainda hoje guardado no Arquivo Goethe-Schiler (227 páginas, GSA - Número de registro 72/2443). Está catalogado por grupos de assunto e registra também dedicatórias e vestígios de leitura deixados nos livros, assim como os exemplares dos manuscritos das próprios obras de Nietzsche.

Com base no catálogo de Steiner, Elisabeth Förster-Nietzsche publicou, no ano 1900 e novamente em 1912, em uma obra sobre a vida e os livros de Nietzsche, um outro catálogo ${ }^{9}$ igualmente ordenado por assunto, porém, provido apenas com dados bibliográficos muito breves. $\mathrm{O}$ interesse por este catálogo hoje se restringe apenas à obtenção de algumas informações sobre a história da biblioteca.

No contexto das atividades para a edição histórico-crítica da obra de Nietzsche, realizada no ano de 1932 por Hans Joachim Mette e Max Oehler, sob a assistência de Adolf Metzner, foi levado a cabo um trabalho de organização da Biblioteca. Os livros foram organizados de forma sistemática e receberam um número de registro. Essa organização está ainda hoje amplamente disponível.

6 Trata-se da primeira edição completa das obras de Nietzsche, intitulada "Großoktav-Ausgabe" e abreviada por "GA". (Nota dos tradutores).

7 BAW e BAB são as abreviaturas para Beck'schen historisch-kritischen Ausgabe, a primeira referindo-se às obras (Werke) e a segunda às cartas (Briefe). Corresponde à edição de 1933 em 5 volumes, organizada por Hans Joachim Mette e Karl Schlechta, publicada pela Editora C.H. Beck com os textos de juventude de Nietzsche (textos de juventude, publicações filológicas e preleções como professor na Basileia), cuja edição se inicia por conta da discussão em torno da obra apócrifa "Vontade de poder". (Nota dos tradutores).

8 A este respeito, coferir novamente P. D'Iorio no livro já mencionado Nietzsches persönliche Bibliothek, p. 36-41 [na página 39, linhas 21 e 24 D’Iorio faz evidentemente uma confusão acerca da abrangência dos dados do Catalogo de Steiner].

9 FÖRSTER-NIETZSCHE, Elisabeth Friedrich Nietzsches Bibliothek. In: Bücher und Wege zu Büchern org. por Arthur Berthold. Berlin Stuttgart: W. Spemann, 1900. p. 427-456. - Publicado novamente em: Deutscher Bibliophilen-Kalender für das Jahr 1913. Wien 1912. p. 103-123. 
Durante esse trabalho surgiu também o fichário datilografado por Adolf Metzner e também existente até hoje na Biblioteca Herzogin Anna Amalia. Mette planejou publicar um "catálogo dos livros de Nietzsche em forma de um apêndice, ordenado de forma sistemática e alfabética, para ser publicado no primeiro volume da obra," ${ }^{10}$ porém, tal plano nunca foi efetivado e, hoje, nem mesmo os manuscritos preparatórios daquele trabalho puderam ser encontrados.

Os trabalhos de 1932 foram ainda, contudo, a base para a publicação do catálogo intitulado Biblioteca Nietzsche ${ }^{11}$ por Max Oehler, em 1942. Por um longo período, este catálogo organizado por Oehler foi a única opção de orientação para a pesquisa sobre Nietzsche, tanto no tocante ao acesso à biblioteca quanto às leituras de Nietzsche. Ele registra uns 887 títulos com aproximadamente 1.100 volumes em 775 posições (números de registro $\mathrm{C} 1$ C 775). Os vestígios de leitura são indicados em sua quantidade por meio de um sistema de pontos simples. Em dois apêndices ao catálogo são assinalados, com apenas breves indicações bibliográficas, as obras de filologia requisitadas por Nietzsche da Escola de Pforta, bem como os empréstimos feitos da biblioteca da universidade da Basileia.

Por vários motivos os três catálogos, o de Steiner, o de Elisabeth Förster-Nietzsche e o de Oehler se diferenciam em suas informações sobre a dimensão da biblioteca de Nietzsche, dentre outros motivos, porque determinados grupos de livros não foram incluídos, ou seja, receberam tratamentos diferentes (maços de papel, cadernos de notas de músicas, obras de Nietzsche). Isto se passou com Elisabeth Förster-Nietzsche e mais tarde também com Oehler, que não levaram em consideração os cadernos de notas musicais pertencentes a Nietzsche, bem como os exemplares dos manuscritos de suas obras, sendo que no caso dos cadernos de notas musicais, eles foram desconsiderados também no catálogo de Steiner.

A biblioteca de Nietzsche não foi nenhuma vez reunida por completo, pelo menos durante o tempo em que seu proprietário esteve vivo e consciente, pois, como homem que viajava constantemente, guardava os livros ou pedia que os guardassem em diferentes localidades. Também no ArquivoNietzsche isto não ocorreu, pois, neste caso, os exemplares manuscritos de sua obra foram mantidos fora dali. Tal reunião não ocorreu tampouco após 1945,

\footnotetext{
10 Protocolo sobre a sétima reunião ordinária dos membros da sociedade dos amigos do ArquivoNietzsche de 7 de Dezembro de 1932. p. 7 (GSA).

11 Nota 3
} 
pois se é certo que grande parte de seus livros foram guardados na atual Biblioteca Herzogin Anna Amalia, muitos livros de Nietzsche se encontram também no Arquivo Goethe-Schiller.

Os livros permaneceram após 1945 primeiramente em "Silberblick", em 1950 eles foram transferidos, juntamente com todos os demais pertences do antigo Arquivo-Nietzsche bem como o espólio de Elisabeth FörsterNietzsche, para o prédio do Arquivo Goethe-Schiller. Os manuscritos póstumos de Nietzsche e a sua biblioteca foram aí estabelecidos e tornaram-se efetivamente acessíveis aos pesquisadores de Nietzsche da Europa ocidental. ${ }^{12}$ Desde 1953 o Arquivo Goethe-Schiller pertence ao Instituto Nacional de Pesquisa e Memória da Literatura clássica alemã, a qual em 1991 foi transformada na atual Fundação Weimar Clássica. Durante a formação do Instituto Nacional de Pesquisa e Memória da literatura clássica alemã foi fundada também uma Biblioteca do Instituto que, em conjunto com a antiga Biblioteca Regional da Turíngia, deu origem à atual Biblioteca Herzogin Anna Amalia. Essa Biblioteca do Instituto, mais tarde denominada como Biblioteca Central da Cultura Clássica Alemã, recebeu também os acervos de livros do Arquivo Goethe-Schiller, entre os quais a biblioteca de Nietzsche (com exceção das acima mencionadas 133 volumes, que permaneceram conjugados com o acervo dos manuscritos n. 71 "Nietzsche") e a biblioteca do antigo Arquivo-Nietzsche. Os livros de ambas as coletâneas foram novamente catalogados, assim como um catálogo sistemático foi levado a efeito. Desde 1955 os livros foram depositados nas salas da biblioteca central no castelo da cidade de Weimar como pertencentes ao acervo de uma coletânea especial e tornada acessível a pesquisadores. Em 1991, quando então passou a se chamar Biblioteca Herzogin Anna Amalia, foi preparada uma sala especial para ambas as coleções. No outono de 2004 os livros passaram a dispor de uma moderna forma de conservação, que corresponde ao local instalado no novo depósito subterrâneo. No inverno de 1996/97 os livros de Nietzsche foram microfilmados mediante apoio financeiro de um comerciante americano. Está prevista, e em parte já preparada, uma cuidadosa restauração dos livros mais danificados bem como um trabalho de proteção aos livros não encadernados. No futuro, para fins de conservação dos livros, a utilização deverá efetuar-se prioritariamente por meio de microfilmes. Num momento posterior, os livros

12 A este respeito, conferir a crônica de HOFFMANN: Zur Geschichte des Nietzsche-Archivs, p. 120-121 e K.-H. Hahn nos Nietzsche-Studien, 18 (1989). p. 17ss. 
de Nietzsche que possuem visíveis vestígios de leitura deverão ser digitalizados e disponibilizados à pesquisa pela internet na seção intitulada "monografia digital" da Biblioteca Herzogin Anna Amalia.

Naturalmente, o que interessa de forma especial à pesquisa nos livros de Nietzsche, além de saber quais livros ele possuiu, são os vestígios de leitura neles deixados. O catálogo de Oehler apresenta ao menos uma primeira informação sobre tais vestígios de leitura, pois utiliza um sistema de pontos e assinala desta forma a intensidade de tais vestígios. O espectro desses vestígios de leitura se estende do livro ainda não aberto, ou seja, se estende com relativa segurança do livro não lido, passando sobre casuais marcações ou sublinhas, orelhas, desenhos de estudante nos momentos de desinteresse na aula, notas isoladas até chegar às marcações intensas, anotações à margem do texto, traduções e resumos, por vezes em folhas desordenadas. ${ }^{13}$ Também sinais do Nietzsche doente certamente são encontrados na forma de rabiscos. Do mesmo modo, encontram-se em alguns livros sinais de relações de amizade com seus contemporâneos na forma de dedicatórias a Nietzsche.

Mazzino Montinari em um estudo breve e fortemente documentado sobre a relação entre a leitura dos fragmentos e a obra de Nietzsche apresenta a seguinte reflexão:

A leitura feita por Nietzsche de outros autores, - registrada (em sua maioria) por meio de citações escondidas em seus escritos, de excertos em fragmentos, de comentários à margem do texto, sublinhas e outros vestígios de leitura nos volumes de sua biblioteca, - é uma parte efetiva de sua obra. Ela pertence, portanto, ao texto, porém, remete, ao mesmo tempo, para além do texto. (MONTINARI, 1987, p. 24; MONTINARI; 1988, p. 137).

Tanto que no tocante ao estudo das fontes Montinari não procede como se estivesse fazendo uma mera pesquisa de antiquário, mas efetua o esclarecimento do "problema do horizonte de um texto"; tal como elucidou pormenorizadamente Andreas Urs Sommer, ${ }^{14}$ para quem a pesquisa de fontes deve produzir uma minuciosa "recontextualização". Porém, o estudo das fontes como uma disciplina crítica exige, ainda, meios de ajuda que são fundamentais,

13 Na "expressão "mitunter auf durchschossenen Blättern", traduzido aqui como "por vezes em folhas desordenadas", o termo "durchschossenen Blättern" corresponde" às folhas em branco, que se encontram entre as provas tipográficas de um livro e que, com a impressão, dão origem sempre a uma folha em branco no corpo do texto. (Nota de esclarecimento feita pelo autor sobre o termo).

14 SOMMER, Andreas. Urs: Vom Nutzen und Nachteil kritischer Quellenforschung. - In: Nietzsche-Studien 29 (2000). p. 302-316. Citação p. 306. 
como o são, por exemplo, as bibliografias ou ainda os catálogos das bibliotecas e dos registros de leitura deixados por grandes pensadores. A este respeito, já bem cedo, Montinari também propõe, como a ordem do dia, que ao lado do trabalho editorial fosse feita a investigação sobre a biblioteca de Nietzsche e suas leituras. Segundo ele, uma meta esclarecedora neste sentido seria "a total reconstrução histórica de sua biblioteca ideal e de suas leituras." ${ }^{15}$ Como uma publicação paralela à KGW (Edição crítica da obra de Nietzsche) e à KGB (Edição crítica das cartas de Nietzsche), ele projetava a edição de um catálogo da Biblioteca de Nietzsche (MÜLLER-LAUTER, 1994, p. 313-314) e com esta finalidade fundou em 1982 o grupo de trabalho intitulado "Biblioteca e Leituras de Nietzsche." Após a morte de Montinari o grupo reforçou seu trabalho de pesquisa sob a direção de Giuliano Campioni e Aldo Venturelli. ${ }^{16}$

Deve-se poder entender Nietzsche também (não apenas: nota para especuladores) historicamente. Por isto é uma tarefa necessária para a pesquisa sobre Nietzsche: a busca por suas fontes, a reconstrução de sua biblioteca ideal, conhecer os contemporâneos com os quais ele debateu, assim como as reais condições de Nietzsche nas relações com indivíduos e círculos de seu tempo, as quais são decisivas por seus efeitos futuros: precursores, contemporâneos e a posteridade de Nietzsche. (MONTINARI, 1982, p. 6).

Estas frases marcam sensivelmente a ideia de Montinari acerca do trabalho fundamental de pesquisa sobre Nietzsche, paralelo aos trabalhos de editoração de seus escritos. Nisso a reconstrução da biblioteca ideal de Nietzsche possui uma posição privilegiada. Naturalmente a biblioteca ideal, a soma de tudo o que Nietzsche possuiu de livros ou emprestou e leu, deve ser considerada apenas como um construto da pesquisa, que tende a querer conhecer toda e qualquer fonte literária. Reconstruí-la plenamente não é possível, e mesmo a consideração de tal ideia já é contestável em alto grau. É comprovado que Nietzsche fazia um uso intensivo também de outras bibliotecas, como a biblioteca escolar em Naumburg e de Pforta, a biblioteca da universidade de Bonn, Leipzig e Basileia, assim como de bibliotecas públicas e municipais em Leipzig, Gênova e Turin.

15 MONTINARI, M. Aufgaben der Nietzsche-Forschung heute. Nietzsches Auseinandersetzung mit der französischen Literatur des 19. Jahrhunderts. - In: Nietzsche heute. Die Rezeption seines Werkes nach 1968. Bern: Stuttgart, 1988. p. 147.

${ }^{16}$ Cf. sobre a história do grupo de trabalho das edições das obras de Nietzsche: "Nietzsche Bibliothek und Lektüre", em especial o prefácio de Campioni e Venturelli publicado no livro aqui mencionado "Nietzsches persönliche Bibliothek", p. 7-31. 
Ocasionalmente ele também tomava emprestados livros de amigos e conhecidos, como se pode observar por meio dos registros encontrados em sua correspondência. Naturalmente a biblioteca de Nietzsche se encontra no centro de tal pesquisa sobre suas leituras, uma pesquisa que hoje é volumosa e que, em parte, já apresenta resultados significativos. Na Bibliografia sobre Nietzsche de Weimar encontram-se ao todo mais de 120 publicações em forma de ensaios e monografias sob as palavras-chave "leituras de Nietzsche", "biblioteca de Nietzsche" e "Nietzsche como usuário de biblioteca". A maioria dessas publicações apareceu após 1982 e boa parte delas nasceu no âmbito das pesquisas do grupo de trabalho "Biblioteca e Leituras de Nietzsche."

\section{O novo catálogo da biblioteca de Nietzsche}

No ano de 2003 foi publicado sob o título "Biblioteca pessoal de Nietzsche" ${ }^{17}$ um novo catálogo dos livros de propriedade de Nietzsche, que registra em um único volume a biblioteca deixada pelo filósofo, portanto, o acervo ainda existente hoje, no geral, a biblioteca tal como foi reconstruída, ao menos até onde isto pode ser ainda esclarecido. Esse catálogo surgiu no âmbito de um longo projeto de pesquisa da Universidade de Pisa sobre a "Biblioteca e Leituras de Nietzsche" nos anos de 1991 a 2001. O grupo de pesquisa dirigido por Giuliano Campioni e Paolo D'Iorio de fato realizou um diligente trabalho (entre outros aspectos, milhares e mais milhares de páginas foram autopsiadas) do qual resultou um catálogo longo e muito apropriado sobre os livros de propriedade de Nietzsche. A qualidade desse trabalho se deve à intensiva investigação sobre os livros de propriedade de Nietzsche, assim como o registro minucioso e a catalogação formal dos vestígios de leitura. Com base no exame e no aproveitamento dos três antigos catálogos, na revisão completa do conjunto dos livros de Nietzsche que estão hoje no acervo da Biblioteca Herzogin Anna Amalia e no Arquivo Goethe-Schiller, e por meio da inclusão de documentos como recibos de compras em livrarias, vendas e devoluções de livros, foi possível investigar posteriormente um grande número de livros e, pela primeira vez, classificá-los. Os documentos permitiram identificar cerca de 230 livros que hoje não mais se encontram no acervo e que, antigamente, pertenceram a Nietzsche.

17 Nietzsches persönliche Bibliothek / org. por Giuliano Campioni, Paolo D'Iorio ..., Berlin, New York, Walter de Gruyter 2003, 736 p. (Supplementa Nietzscheana ; Bd. 6). - a respeito minha resenha em: Nietzsche-Studien 33 (2004). p. 394-406, aqui principalmente as páginas 396-402. 
Acrescente-se a isso o registro de livros que haviam sido omitidos pelas pessoas que trabalharam até então no acervo do antigo Arquivo-Nietzsche ou que não foram considerados, em função da definição do que seria a "Biblioteca de Nietzsche", embora inequivocamente pertenceram ao conjunto dos livros de Nietzsche (exemplares manuscritos das obras de Nietzsche, partituras musicais). No novo catálogo foram registrados também diferentes livros, os quais haviam sido extraviados ao longo da história cheia de vicissitudes da biblioteca. Todas estas averiguações fazem do novo catálogo um instrumento imprescindível, elas oferecem uma contribuição essencial à reconstrução da dimensão histórica da biblioteca de Nietzsche e tornam acessíveis novas fontes para a pesquisa sobre Nietzsche. Desvantajoso para a utilização do catálogo é, contudo, a falta nele de um registro das obras por assunto, o que torna necessário o constante retorno ao catálogo de Oehler do ano de 1942.

Por que foi necessário um novo catálogo sobre a biblioteca de Nietzsche? Para uns o catálogo de Oehler está esgotado há muito tempo, pois em 1942 foi publicado apenas em uma pequena edição como a contribuição anual da sociedade de amigos do Arquivo-Nietzsche, sendo por isso acessível apenas em algumas poucas bibliotecas. As indicações bibliográficas são muito simples, porém, são suficientes para permitir identificar de forma clara as edições. As indicações de vestígios de leitura são feitas por meio de um sistema de pontuação simples sem pretensão científica. Alguns vestígios de leitura não foram observados por Oehler. Do mesmo modo, como já foi dito, partes importantes dos livros que pertenciam a Nietzsche não foram registradas. O catálogo de Oehler descreve o status quo de 1932/1940, contudo, não empreende qualquer averiguação posterior dos livros, os quais Nietzsche possuiu e que, contudo, por diferentes motivos não se encontravam mais no seu acervo. De um modo geral, porém, o catálogo de Oehler foi um documento útil e também muito empregado nas pesquisas sobre Nietzsche por mais de 60 anos, o qual, em função de sua organização sistemática, coerentemente compreensível. O próprio Max Oehler tinha consciência do caráter preliminar de seu trabalho, tal como ele deu a entender em seu prefácio:

Também este catálogo, que toma como referência os livros disponíveis da biblioteca de Nietzsche, deverá constituir aas bases para uma tentativa talvez ainda mais ousada, de reconstruir a biblioteca em sua plenitude, o que se fará também com a reunião, ainda consideravelmente difícil, de tudo o que Nietzsche conheceu de literatura em geral. (OEHLER, 1942, p. VIII). ${ }^{18}$

18 Nietzsches Bibliothek / [Max Oehler (Org.)], 1942, p. VIII. 


\section{Biblioteca do antigo Arquivo-Nietzsche em Weimar (Números de registro C 776 - C 5141)}

A segunda parte da coletânea-Nietzsche na Biblioteca de Weimar compreende cerca de 6.000 volumes da biblioteca do antigo Arquivo-Nietzsche. Ela é essencialmente uma coletânea feita entre os anos de 1892 até 1945/45, de obras sobre Nietzsche e de exemplares da maioria das tiragens de sua obra. Além disto, faz parte desse acervo também uma parte da biblioteca privativa de Elisabeth Förster-Nietzsche composta por grande número de livros com dedicatórias de seus contemporâneos. Também estão disponíveis alguns periódicos filosóficos e culturais, que o ArquivoNietzsche assinava, dentre os quais um exemplar integral e muito bonito e do periódico "PAN" da editora Insel (Insel-Verlag) de Leipzig. Completa ainda a coleção, alguns livros de conteúdo filológico originalmente de propriedade de Erwin Rohde (C 776 - C 804).

A parte desse acervo mais interessante para a pesquisa é aquela na qual estão incluídas as tiragens que são relevantes para os trabalhos de edição do Arquivo-Nietzsche, portanto, as primeiras publicações das obras de Nietzsche; outras tiragens, que foram levadas a público na época em que o filósofo era vivo; bem como alguns dos exemplares dos manuscritos com sinais feitos à mão de seus trabalhos de reconfiguração ou acréscimos ao texto inicial; e também provas tipográficas com as correções de Nietzsche. As primeiras edições e provas tipográficas estão hoje disponibilizadas também em microfilmes. Além disso, pertence a esse acervo ainda as impressões e algumas provas editoriais das edições completas da obra de Nietzsche com os sinais do trabalho de diferentes editores desde Peter Gast, além de Fritz Kögel, Eduard von der Hellen, até Ernst e August Horneffer, cujo trabalho de filologia sobre os escritos de Nietzsche não perdeu o fôlego até os dias de hoje, ${ }^{19}$ sobretudo em função da convivência dos autores com os fragmentos póstumos de Nietzsche.

19 Também meu ensaio "Philologisches, Allzuphilologisches - zum editorischen Umgang mit Nietzsches Menschliches, Allzumenschliches durch Peter Gast (d.i. Heinrich Köselitz)" [in: Zur unterirdischen Wirkung von Dynamit : Vom Umgang Nietzsches mit Büchern zum Umgang mit Nietzsches Büchern / org. por Michael Knoche ..., Wiesbaden 2006, p. 155-173], com base no legado de provas textuais na biblioteca do antigo Arquivo-Nietzsche, em que são apresentadas as graves violações feitas por Peter Gast (1892/93) no texto de, Humano, Demasiado Humano" deixado por Nietzsche e anuladas por Eduard von der Hellen (1894/95). 


\section{Coleção de obras sobre Nietzsche da biblioteca de Weimar (Registros C5142ss)}

A terceira parte da coletânea-Nietzsche da Biblioteca de Weimar forma uma coleção de literatura primária e secundária que foram publicadas, sobretudo depois de 1955. Essa coleção é iniciada nos anos 50, de forma mais ou menos acidental, a partir dos livros entregues (presente, confisco) à antiga Biblioteca Central de clássicos alemães ou ao Arquivo GoetheSchiller. Alguns livros foram adquiridos de antiquários. Contudo, nos anos 50 e 60 a biblioteca compreendia apenas alguns poucos livros. A partir dos anos 70, sobretudo em função das atividades de Montinari em Weimar, os livros do acervo foram aumentando, em sua maioria, entregues como exemplares comprovativos. Somente a partir da virada de 1989/90 é que a Biblioteca Herzogin Anna Amalia esteve em condições de levar a termo essa coletânea. A partir de então, o critério de aquisição dos livros recebeu uma nova determinação: estão sendo reunidas, para efeitos de documentação da história das edições, todas as edições da obra de Nietzsche e suas traduções. Também foi reunida toda a literatura secundária publicada em língua alemã, assim como uma volumosa literatura secundária em língua estrangeira. Com exceção das publicações de literatura secundária originadas de traduções. Segue-se ainda uma complementação da bibliografia dos anos anteriores, a partir dos antiquários, na medida em que os recursos financeiros vão permitindo. A meta é, em poucos anos, preparar e colocar à disposição para a pesquisa uma extensa coletânea de obras sobre Nietzsche também dos anos posteriores a 1945. Até o momento atual essa coletânea compreende cerca de 6.000 livros e pequenos escritos. Todos os periódicos substanciais sobre Nietzsche também estão disponibilizados em séries completas (Nietzsche-Studien, Nietzscheforschung, New Nietzsche studies, Estudios Nietzsche, Cadernos Nietzsche, Journal of Nietzsche studies, Etudes Nietzschéennes e outros). Numerosas publicações, sobretudo as que apareceram depois de 1970, foram catalogados de forma sistemática e se encontram numa área de livre acesso do novo centro de estudos da Biblioteca Herzogin Anna Amalia (este acervo é composto por mais de 2.000 volumes), e podem ser acessados diretamente pelos pesquisadores de Nietzsche para seus trabalhos. Novos livros chegam, quase diariamente, para essa coleção. 


\section{Referências}

D'IORIO, P. Geschichte der Bibliothek Nietzsches und ihrer Verzeichnisse. In: Nietzsches persönliche Bibliothek. Berlin, New York: Walter de Gruyter, 2003. p. 7-31, 33-77.

FÔRSTER-NIETZSCHE, E. Friedrich Nietzsches Bibliothek. In: Bücher und Wege zu Büchern. Organizado por Arthur Berthold. Berlin, Stuttgart: W. Spemann, 1900. p. 427-456.

HANK, H. Das Neiech - Archive. In: Nietzsche-Studien 18. Berlin: Walter de Gruyter, 1989. p. 17-19.

HOFFMANN, D. M. Zur Geschichte des Nietzsche-Archivs. New York: Walter de Gruyter, 1991. (Supplementa Nietzscheana, 2).

METTE, H. J. Sachlicher Vorbericht. In: Nietzsche: Werke und Briefe. Historisch-Kritische Gesamtausgabe. Jugendschriften 1854-1861. München, 1933. v. 1. p. 102-103.

MONTINARI, M. Zum Verhältnis Lektüre-Nachlaß-Werk bei Nietzsche. In: Editio 1, p. 245-249, 1987.

Aufgaben der Nietzsche-Forschung Heute. Nietzsches Auseinandersetzung mit der Französischen Literatur des 19. Jahrhunderts. In: Nietzsche heute. Die Rezeption seines Werkes nach 1968. Bern: Stuttgart, 1988. p. 136-148.

Nietzsche Lesen. Berlin, New York: Walter de Gruyter, 1982.

MÜLLER-LAUTER, W. Zwischenbilanz zur Weiterführung der von Montinari Mitbegründeten Nietzsche-Editionen Nach 1986. In: Nietzsche-Studien 23. Berlin: Walter de Gruyter, 1994. p. 307-316.

OEHLER, M. Nietzsches Bibliothek. Weimar: Walter de Gruyter, 2003. p. VIII (Supplementa Nietzscheana, Bd. 6).

Nietzsches Bibliothek. Weimar: Walter de Gruyter, 1942. p. 8. (Supplementa Nietzscheana).

SOMMER, A. Urs. Vom Nutzen und Nachteil Kritischer Quellenforschung. In: Nietzsche-Studien 29. Berlin: Walter de Gruyter, 2000. p. 302-316. 
WILLAMOWITZ-MOELLENDORFF, E. von. Neuerscheinungen zur Erforschung von Nietzsches Bibliotheck und Lektüre Sowie zur Publikationsgeschichte Seiner Werke. In: Nietzsche-Studien 33. Berlin: Walter de Gruyter, 2004. p. 394-406.

Philologisches, Allzuphilologisches - zum Editorischen Umgang mit Nietzsches Menschliches, Allzumenschliches durch Peter Gast (d.i. Heinrich Köselitz). In: KNOCHE, M. Zur Unterirdischen Wirkung von Dynamit: vom Umgang Nietzsches mit Büchern zum Umgang mit Nietzsches Büchern. Wiesbaden: Walter de Gruyter, 2006. p. 155-173.

Recebido:22 /04/2008

Received: 04/22/2008

Aprovado: 04/07/2008

Approved: 07/04/2008 